\title{
Microbiostasis by Nutrient Deficiency Shown in Natural and Synthetic Soils
}

\author{
By W. C. HO† AND W. H. KO* \\ Department of Plant Pathology, University of Hawaii, Beaumont Agricultural Research Center, \\ Hilo, Hawaii 96720, USA
}

(Received 11 March 1986; revised 28 May 1986)

\begin{abstract}
The germination pattern of six species of fungi on synthetic soil containing antibiotic-producing or non-antibiotic-producing micro-organisms was similar to that on natural soil. Sterilization by autoclaving destroyed the fungistatic effect of both natural and synthetic soils. Mixed microorganisms were more effective than bacteria, actinomycetes or fungi alone in inducing fungistasis in synthetic soil. The percentage germination of Exserohilum rostratum and Bipolaris maydis on both natural and synthetic soils increased with increase in the proportion of silica sand added. Bacteriostasis, actinostasis and fungistasis occurred concurrently in the synthetic soil, which also induced lysis of mycelia of Neurospora tetrasperma. Preincubation on natural or synthetic soil rendered nutrient agarose blocks incapable of supporting germination of nutrientdependent fungi without reducing their ability to support germination of nutrient-independent fungi. Individual groups of micro-organisms were not as effective as mixed micro-organisms in causing diffusion of nutrients from agarose blocks to synthetic soil.
\end{abstract}

\section{INTRODUCTION}

The inability of micro-organisms to multiply when added to natural soil was observed as early as 1909 for bacteria (Russell \& Hutchinson, 1909) and 1940 for actinomycetes and fungi (Katznelson, 1940). Such antagonistic phenomena of soil against bacteria, actinomycetes and fungi have been termed bacteriostasis (Brown, 1973), actinostasis (Ko \& Chow, 1977) and fungistasis (Dobbs \& Hinson, 1953), respectively, and called microbiostasis collectively (Ko \& Chow, 1976). Bacteriostasis, actinostasis and fungistasis exist concurrently in natural soils (Ho \& Ko, 1982; Ko \& Ho 1984). However, their antagonistic potential are differentially affected by environmental and edaphic factors (Ko \& Ho, 1984; Ho \& Ko, 1985). Lytic action on mycelia of most fungi is another unique antagonistic phenomenon of natural soil (Lockwood, 1960). Ko \& Lockwood (1970) found that mycolysis occurred even when sterility of mycelia was maintained during incubation on soil by interposition of a membrane.

Ko \& Lockwood (1967) suggested that sensitivity of nutrient-dependent spores to fungistasis is the result of the absence of available nutrients in the soil, and postulated the existence of a nutrient sink in soil created by microbial competition to account for fungistasis of nutrientindependent spores. Lysis of fungal mycelia in soil has been shown to be due to autolysis induced also by the action of a nutrient sink in natural soil (Ko \& Lockwood, 1970). Based on the information currently available, nutrient deprivation has been considered to be the most likely overriding explanation for microbiostasis of soil (Ko \& Chow, 1977; Ko, 1982; Lynch, 1982; Ko \& Ho, 1984; Lockwood, 1984).

Inhibition of the spore germination and lysis of fungal mycelia under a leaching system have been used as supporting evidence for the importance of a nutrient sink in the creation of such phenomena in natural soil (Ko \& Lockwood, 1967, 1970; Hsu \& Lockwood, 1973). Although the

† Present address: National Pingtung Institute of Agriculture, Pingtung, Taiwan. 
leaching system provides an inhibitor-free condition for studying the antagonistic phenomena in soil, the assumption that microbial activity creates a nutrient sink in soil cannot be tested in such a system. Therefore, a synthetic soil was developed for assessing the role of micro-organisms in the creation of antagonistic phenomena in soil.

\section{METHODS}

Micro-organisms. Conidia of Bipolaris maydis (Nishikado) Shoemaker, B. stenospila (Drechsler) Shoemaker, Exserohilum rostratum (Drechsler) Leonard \& Suggs emend. Leonard, Mucor ramannianus Moller, Penicillium frequentans Westling and $P$. funiculosum Thom were obtained by growing each fungus under continuous fluorescent light for 6-8 d at $24^{\circ} \mathrm{C}$ on V-8 juice agar (Aragaki, 1964). Ascospores of Neurospora tetrasperma were obtained as described by Ko \& Lockwood (1967) and used after heat activation at $58{ }^{\circ} \mathrm{C}$ for $20 \mathrm{~min}$. Penicillium funiculosum was obtained from K. G. Rohrbach and the other species from M. Aragaki and J. L. Lockwood. Antibiotic-producing or non-antibiotic-producing bacteria, actinomycetes and fungi were isolated from soil as previously described (Ho \& Ko, 1982).

Synthetic soil. The inorganic component of the synthetic soil consisted of $65 \%>0 \cdot 2 \mathrm{~mm}$ silica sand, $20 \%$ $<0.2 \mathrm{~mm}$ silica sand, $8 \%$ kaolinite and $7 \%$ montmorillonite. Silica sand was washed by shaking $100 \mathrm{~g}$ in $150 \mathrm{ml}$ $1 \mathrm{M}-\mathrm{HCl}$ in a $250 \mathrm{ml}$ flask on a shaker. After $24 \mathrm{~h}$ the $\mathrm{HCl}$ solution was replaced with fresh distilled water daily for $3 \mathrm{~d}$. The washed silica sand was dried in an oven at $110^{\circ} \mathrm{C}$. The inorganic component was mixed with Canadian peat as the organic component at a ratio of $1: 9(\mathrm{w} / \mathrm{w})$. Before use, $200 \mathrm{ml}$ moist Canadian peat was autoclaved for $15 \mathrm{~min}$ and washed by shaking in $1500 \mathrm{ml}$ distilled water in a $2000 \mathrm{ml}$ flask for 1 week. The distilled water was changed every day. The washed Canadian peat was adjusted to $\mathrm{pH} 7$ with $1 \mathrm{M}-\mathrm{NaOH}$ and dried in an oven at $50^{\circ} \mathrm{C}$ for $3 \mathrm{~d}$. Since extracts of natural soil contained about $4.2 \mu \mathrm{g}$ carbohydrates $\mathrm{ml}^{-1}$ and $0.7 \mu \mathrm{g}$ amino acids ml ${ }^{-1}$ (Ko \& Lockwood, 1967), $10 \%$ (v/v) Hoagland's solution (Hoagland \& Arnon, 1950) supplemented with $6 \mu \mathrm{g}$ glucose $\mathrm{ml}^{-1}$ and $1 \mu \mathrm{g}$ Casamino acids $\mathrm{ml}^{-1}$ was used as the soil solution for the synthetic soil. The ratio of soil solution and soil solid substance was $4: 10(\mathrm{v} / \mathrm{w})$.

The numbers of micro-organisms in each component of synthetic soil were determined by the dilution plate method as described previously (Ho \& Ko, 1982). No micro-organisms were detected in silica sand or kaolinite. There were an average of 5 bacteria and 1.7 fungi in $1 \mathrm{~g}$ dry Canadian peat, and 1390 bacteria and 1130 actinomycetes in $1 \mathrm{~g}$ montmorillonite. Before addition of micro-organisms, the numbers of bacteria, actinomycetes and fungi in $1 \mathrm{~g}$ synthetic soil were 88,71 and 0 , respectively. Suspensions of micro-organisms were obtained from 7-d-old fungi grown on V-8 agar, and 4-d-old bacteria and 14-d-old actinomycetes grown on nutrient agar. Suspensions of fungi, actinomycetes or bacteria, each consisting of five different isolates, were thoroughly mixed with non-inoculated synthetic soil at the ratio of $1: 10(\mathrm{v} / \mathrm{w})$. This soil was further mixed with non-inoculated synthetic soil at the same ratio. The resulting synthetic soil contained about $6 \times 10^{7}$ bacteria, $7 \times 10^{6}$ actinomycetes and $2 \times 10^{6}$ fungi $\mathrm{g}^{-1}$. The inoculated synthetic soil was incubated at $24^{\circ} \mathrm{C}$ for at least 1 month before use. The final populations of bacteria, actinomycetes and fungi were about $8 \times 10^{7}, 2 \times 10^{6}$, and $5 \times 10^{5}$ $(\mathrm{g} \text { dry soil })^{-1}$, respectively. The $\mathrm{pH}$ of the synthetic soil was about $6 \cdot 2$.

Germination tests. One drop (approximately $0.05 \mathrm{ml}$ ) of spore suspension was spread on a sterile polycarbonate membrane $(0.2 \mu \mathrm{m}, 25 \mathrm{~mm}$ diam.; Nuclepore $\mathrm{Co}$.) placed on a block $(15 \times 15 \times 6 \mathrm{~mm})$ of natural or synthetic soil in a small Petri plate $(60 \times 15 \mathrm{~mm})$, and incubated at $24^{\circ} \mathrm{C}$. The incubation time for ascospores of $N$. tetrasperma and conidia of $B$. maydis, B. stenospila and $E$. rostratum, which are nutrient-independent, was $5 \mathrm{~h}$, and that for conidia of $M$. ramannianus, $P$. frequentans and $P$. funiculosum, which are nutrient-dependent, was $16 \mathrm{~h}$. After incubation, each polycarbonate membrane was transferred to a glass slide and spores on the membrane were stained with cotton blue ( $100 \mathrm{ml}$ aniline blue in $100 \mathrm{ml} 85 \%$ lactic acid). At least 200 spores were counted for each treatment. Two replicates were used and all experiments were done at least twice.

Assay of soil microbiostasis. If microbiostasis exists in a given soil, the number of micro-organisms should either decrease or remain more or less constant in it (Ko \& Chow, 1977). If there was no increase in numbers of bacteria, actinomycetes and fungi in soil during a $3 \mathrm{~d}$ interval, the presence of bacteriostasis, actinostasis and fungistasis in soil, respectively, was indicated (Ho \& Ko, 1982). Diluted soil suspensions prepared on days 0 and 3 were plated on PCNB-soil extract agar (Farley \& Lockwood, 1968), alkaline water agar (Ho \& Ko, 1980b) and surfactant-PDA (Steiner \& Watson, 1965) for determining populations of bacteria, actinomycetes and fungi, respectively. Five plates were used for each treatment and colony numbers were determined after $7 \mathrm{~d}$ for bacteria and fungi, and $14 \mathrm{~d}$ for actinomycetes at $24^{\circ} \mathrm{C}$.

Detection of a nutrient sink. Highly purified agarose (SeaKem HGT-P Agarose, Marine Colloids Division, FMC Co., Rockland, Maine, USA), which did not support germination of nutrient-independent fungi (Ho \& Ko, $1980 a)$, was used to study the ability of micro-organisms to create a nutrient sink in soil. Agarose blocks $(0.8 \%$ SeaKem agarose, $100 \mu \mathrm{g}$ glucose $\mathrm{ml}^{-1}$ and $100 \mu \mathrm{g}$ peptone $\mathrm{ml}^{-1}$ ) were placed on polycarbonate membranes and incubated on natural or synthetic soil. After incubation at $24^{\circ} \mathrm{C}$ for $24 \mathrm{~h}$, agarose blocks were transferred to sterile Petri plates and tested for spore germination as previously described. 
To determine the rate of diffusion of nutrients from agarose blocks, $0 \cdot 8 \%$ SeaKem agarose was supplemented with $800 \mu \mathrm{g}$ glucose $\mathrm{ml}^{-1}$ and $250 \mu \mathrm{g}$ asparagine $\mathrm{ml}^{-1}$. Agarose blocks placed on sterile polycarbonate membranes were incubated on synthetic soil and removed at different times during incubation at $24^{\circ} \mathrm{C}$. Nutrients were extracted by shaking three blocks in $5 \mathrm{ml}$ sterile distilled water for $3 \mathrm{~min}$. The extract was filtered through a polycarbonate membrane $(0.2 \mu \mathrm{m})$. Carbohydrates and amino acids in the extract were determined by the anthrone test (Morris, 1958) and ninhydrin test (Moore \& Stein, 1954), respectively.

\section{RESULTS}

\section{Antagonistic phenomena in synthetic soil}

Nutrient-independent fungi ( $N$. tetrasperma, B. maydis, B. stenospila and $E$. rostratum) germinated $91-99 \%$ but nutrient-dependent fungi ( $P$. frequentans and $P$. funiculosum) germinated only $0-33 \%$ on the components of synthetic soil separated by a polycarbonate membrane (Table 1). The germination pattern was similar to that in distilled water, indicating the absence of inhibitory substances and nutrients in these components.

The germination pattern on synthetic soil containing antibiotic-producing or non-antibioticproducing micro-organisms was similar to that on natural soil (Table 2). Ascospores of $N$. tetrasperma, which were not sensitive to fungistasis in natural soil, germinated freely on synthetic soils. Conidia of $B$. maydis, $B$. stenospila, $E$. rostratum, $P$. frequentans and $P$. funiculosum, which were sensitive to soil fungistasis, failed to germinate or germinated poorly on synthetic soils. Autoclaving destroyed the fungistatic effect of both natural and synthetic soils. Because similar results were obtained with synthetic soils inoculated with antibiotic-producing or non-antibiotic-producing micro-organisms, only synthetic soil with non-antibiotic-producing micro-organisms was used in the subsequent experiments.

The ability of different groups of micro-organisms to induce fungistasis in soil was determined by spore germination on synthetic soils inoculated with bacteria, actinomycetes, fungi or representative species of each group. Ascospores of $N$. tetrasperma germinated completely while conidia of $M$. ramannianus and $P$. frequentans failed to germinate on any of the synthetic soils tested (Table 3). When B. maydis was used as the test organism, mixed micro-organisms were more effective than bacteria, actinomycetes and fungi in inducing fungistasis in synthetic soils (Table 3); germination of conidia on synthetic soil with mixed micro-organisms was similar to that on natural soil.

Natural soil and synthetic soil containing mixed micro-organisms were mixed with various amounts of silica sand to dilute the micro-organisms, and germination of conidia of $E$. rostratum was tested on these soils. The percentage germination on both natural and synthetic soils increased with increasing proportion of silica sand (Fig. 1). Similar results were obtained when $B$. maydis was used as the test organism.

The numbers of bacteria, actinomycetes and fungi either decreased or remained more or less constant for $3 \mathrm{~d}$ on synthetic soil containing mixed micro-organisms (Table 4), indicating the concurrent existence of bacteriostasis, actinostasis and fungistasis. When synthetic soil was autoclaved and reinoculated with $1 \%$ natural soil, the populations of bacteria, actinomycetes and fungi all increased in $3 \mathrm{~d}$, indicating the destruction of microbiostasis by autoclaving.

Lysis of fungal mycelia was tested by placing ascospores of $N$. tetrasperma on a polycarbonate membrane laid on synthetic soil. The fungus germinated within $5 \mathrm{~h}$ and lysis of mycelia was noticeable within $36 \mathrm{~h}$ (Fig. 2). More than $50 \%$ of the mycelia had lysed after $60 \mathrm{~h}$ and all mycelia had disappeared after $84 \mathrm{~h}$. The mycelia of $N$. tetrasperma remained intact after $84 \mathrm{~h}$ on sterilized synthetic soil.

\section{Nutrient sink in synthetic soil}

To study the ability of micro-organisms to create a nutrient sink in soil it is necessary to incorporate known amounts of nutrients into a nutrient-free material to be placed on soil. A highly purified agarose (SeaKem HGT-P agarose), which supported germination of nutrientindependent fungi but not nutrient-dependent fungi (Ho \& Ko, 1980), was selected for this study. Agarose $\left(0 \cdot 8 \%\right.$ SeaKem agarose, $100 \mu \mathrm{g}$ glucose $\mathrm{ml}^{-1}$ and $100 \mu \mathrm{g}$ peptone $\left.\mathrm{ml}^{-1}\right)$ blocks 
Table 1. Percentage germination of fungal spores on polycarbonate membranes placed on each component of synthetic soil

The data are from one of two experiments with similar results. More than 200 spores were counted for each treatment in each experiment.

$\begin{array}{lccccc}\text { Test fungus* } & \text { Silica sand } & \text { Montmorillonite } & \text { Kaolinite } & \text { Canadian peat } & \text { Water } \\ \text { N. tetrasperma } & 96 & 94 & 96 & 91 & 93 \\ \text { B. maydis } & 98 & 95 & 99 & 96 & 97 \\ \text { B. stenospila } & 95 & 97 & 97 & 97 & 90 \\ \text { E. rostratum } & 96 & 98 & 96 & 92 & 89 \\ P \text {. frequentans } & 1 & 3 & 2 & 30 & 0 \\ P \text {. funiculosum } & 0 & 5 & 0 & 10 & 0\end{array}$

* Ascospores of $N$. tetrasperma and conidia of the other species were used.

Table 2. Percentage germination of fungal spores on polycarbonate membranes placed on natural soil and synthetic soil

The data are from one of two experiments with similar results. More than 200 spores were counted for each treatment in each experiment.

\begin{tabular}{|c|c|c|c|c|c|c|c|}
\hline \multirow[b]{3}{*}{ Test fungus* } & \multicolumn{3}{|c|}{ Non-sterilized } & \multicolumn{3}{|c|}{ Sterilized } & \multirow[b]{3}{*}{ Water } \\
\hline & \multirow{2}{*}{$\begin{array}{c}\text { Natural } \\
\text { soil }\end{array}$} & \multicolumn{2}{|c|}{ Synthetic soil $\dagger$} & \multirow{2}{*}{$\begin{array}{c}\text { Natural } \\
\text { soil }\end{array}$} & \multicolumn{2}{|c|}{ Synthetic soil $\dagger$} & \\
\hline & & NAP & AP & & NAP & AP & \\
\hline N. tetrasperma & 93 & 94 & 96 & 97 & 92 & 92 & 93 \\
\hline B. maydis & 4 & 9 & 5 & 95 & 99 & 98 & 97 \\
\hline B. stenospila & 3 & 2 & 3 & 92 & 98 & 96 & 97 \\
\hline E. rostratum & 9 & 6 & 9 & 96 & 97 & 95 & 96 \\
\hline P. frequentans & 0 & 0 & 0 & 93 & 99 & 99 & 0 \\
\hline P. funiculosum & 0 & 0 & 0 & 85 & 94 & 96 & 0 \\
\hline
\end{tabular}

* Ascospores of $N$. tetrasperma and conidia of the other species were used.

+ Synthetic soil was inoculated with five isolates each of non-antibiotic-producing (NAP) or antibioticproducing (AP) bacteria, actinomycetes and fungi, and incubated at $24{ }^{\circ} \mathrm{C}$ for at least 1 month before use.

Table 3. Percentage germination of fungal spores on polycarbonate membranes placed on synthetic soils containing different non-antibiotic-producing micro-organisms

Synthetic soils were inoculated with (1) five isolates each of bacteria, actinomycetes and fungi, (2) five isolates of bacteria, (3) five isolates of actinomycetes and (4) five isolates of fungi, and incubated at $25^{\circ} \mathrm{C}$ for at least one month before use. The final populations of micro-organisms in $1 \mathrm{~g}$ soil were: $6.1 \times 10^{7}$ bacteria, $3.6 \times 10^{6}$ actinomycetes and $1.6 \times 10^{6}$ fungi; (2) $1.0 \times 10^{8}$ bacteria; (3) $8.1 \times 10^{6}$ actinomycetes; and (4) $4.5 \times 10^{6}$ fungi. The data are from one of two experiments with similar results. More than 200 spores were counted for each treatment in each experiment. Conidia of $M$. ramannianus and $P$. frequentans did not germinate in any of the conditions tested.

\begin{tabular}{|c|c|c|c|c|c|c|}
\hline \multirow[b]{2}{*}{ Test fungus* } & & \multirow{2}{*}{$\begin{array}{c}\text { Natural } \\
\text { soil }\end{array}$} & \\
\hline & Mixed & Bacteria & Actinomycetes & Fungi & & Water \\
\hline N. tetrasperma & 97 & 97 & 96 & 98 & 95 & 96 \\
\hline B. maydis & 4 & 57 & 20 & 34 & 3 & 99 \\
\hline
\end{tabular}

* Ascospores of N. tetrasperma and conidia of B. maydis were used. 


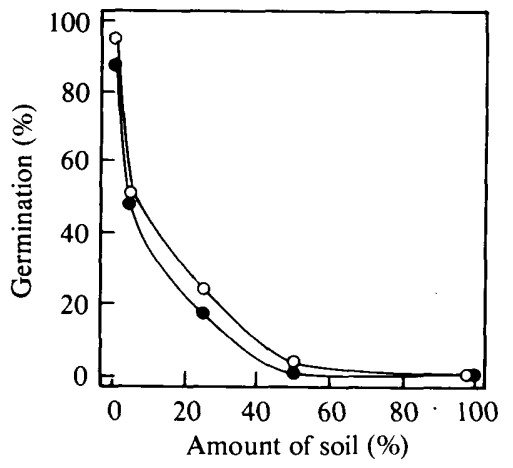

Fig. 1. Spore germination of $E$. rostratum on natural $(O)$ or synthetic soil $(O)$ soil mixed with various amounts of silica sand to dilute the micro-organisms. Synthetic soil contained five isolates each of nonantibiotic-producing bacteria, actinomycetes and fungi.
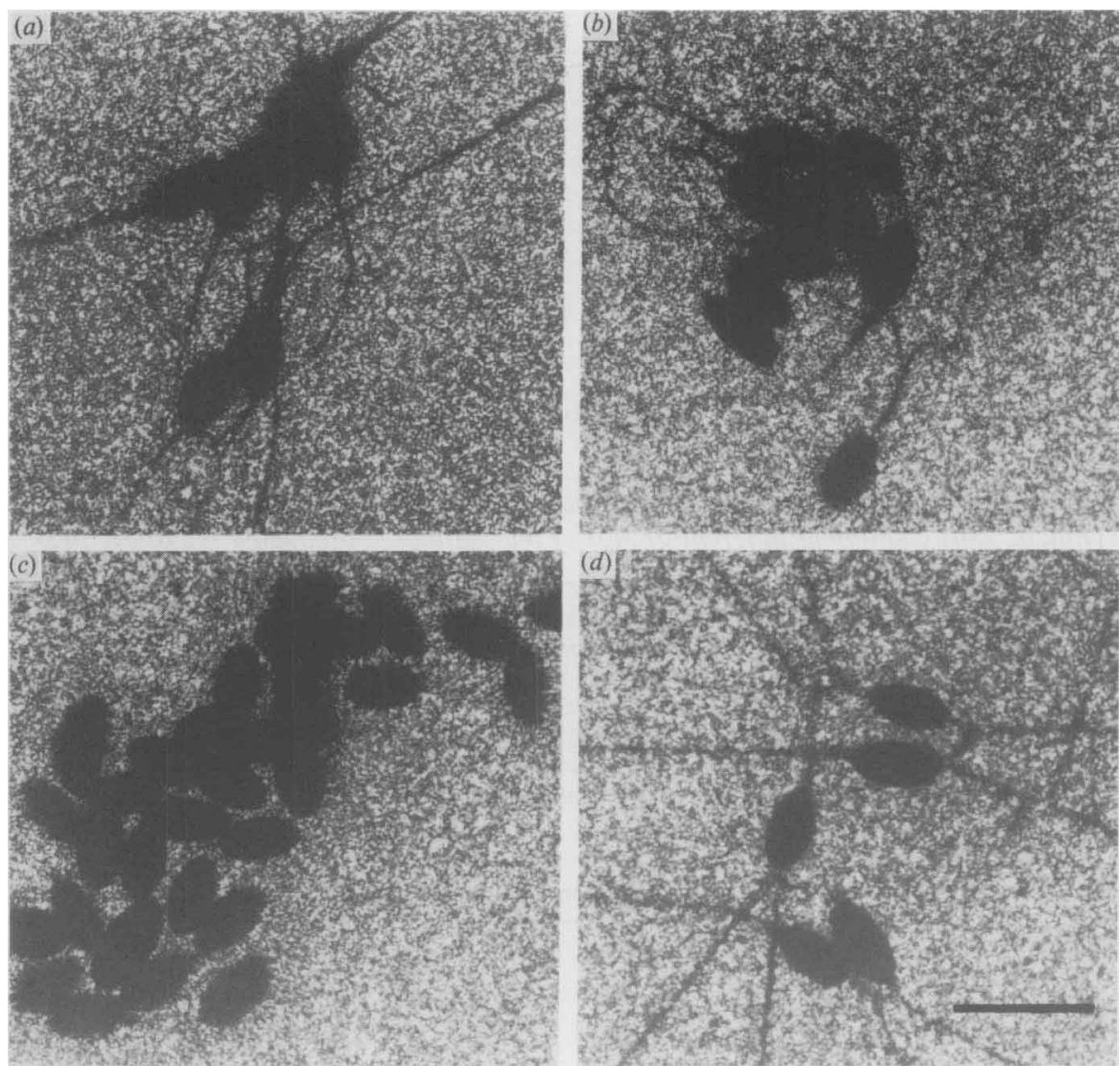

Fig. 2. Lysis of $N$. tetrasperma mycelia on polycarbonate membranes placed on synthetic soil containing non-antibiotic-producing micro-organisms $(a)$ for $36 \mathrm{~h},(b)$ for $60 \mathrm{~h}$, and $(c)$ for $84 \mathrm{~h}$. (d) Mycelia incubated on sterilized synthetic soil for $84 \mathrm{~h}$ (control). Bar, $2 \mu \mathrm{m}$. 
Table 4. Microbiostasis in synthetic soil

Synthetic soil was inoculated with five isolates each of non-antibiotic-producing bacteria, actinomycetes and fungi, and incubated at $24^{\circ} \mathrm{C}$ for at least 3 months before the experiment. Six plates were used for each treatment, and experiments were repeated at least once. The results are given as no. ( $\mathrm{g}$ dry soil) ${ }^{-1}$; values followed by the same letter for each group of micro-organisms between $0 \mathrm{~d}$ and $3 \mathrm{~d}$ are not significantly different at $P=0.05$ based on Student's $t$-test.

\begin{tabular}{|c|c|c|c|c|}
\hline \multirow[b]{2}{*}{ Type of micro-organism } & \multicolumn{2}{|c|}{ Non-sterilized } & \multicolumn{2}{|c|}{ Sterilized } \\
\hline & $0 \mathrm{~d}$ & $3 \mathrm{~d}$ & $0 \mathrm{~d}$ & $3 \mathrm{~d}$ \\
\hline $\begin{array}{l}\text { Bacteria } \\
\text { Actinomycetes } \\
\text { Fungi }\end{array}$ & $\begin{array}{l}6.9 \times 10^{7} a \\
4.3 \times 10^{6} a \\
5.9 \times 10^{5} a\end{array}$ & $\begin{array}{l}6.9 \times 10^{7} a \\
2.3 \times 10^{6} b \\
6.2 \times 10^{5} a\end{array}$ & $\begin{array}{l}4 \cdot 1 \times 10^{5} a \\
6 \cdot 5 \times 10^{4} a \\
2 \cdot 8 \times 10^{2} a\end{array}$ & $\begin{array}{l}5.5 \times 10^{7} b \\
1.7 \times 10^{5} b \\
1.1 \times 10^{4} b\end{array}$ \\
\hline
\end{tabular}

Table 5. Percentage germination of fungal spores on nutrient agarose blocks preincubated on natural soil or synthetic soil containing non-antibiotic-producing micro-organisms

Synthetic soil was inoculated with five isolates each of bacteria, actinomycetes and fungi, and incubated at $24^{\circ} \mathrm{C}$ for at least 1 month before the experiment. Nutrient agarose blocks $(0 \cdot 8 \%$ SeaKem agarose, $100 \mu \mathrm{g}$ glucose $\mathrm{ml}^{-1}$ and $100 \mu \mathrm{g}$ peptone $\mathrm{ml}^{-1}$ ) placed on polycarbonate membranes were incubated on surface of natural or synthetic soil at $24^{\circ} \mathrm{C}$ for $24 \mathrm{~h}$, then transferred to sterile Petri dishes and tested for spore germination. The data are from one of two experiments with similar results. More than 200 spores were counted in each treatment for each experiment.

Test fungus*
N. tetrasperma
B. maydis
B. stenospila
E. rostratum
M. ramannianus
P. frequentans
P. funiculosum

Natural soil
98
100
96
91
2
1
1
Synthetic soil with Synthetic soil with micro-organisms no micro-organisms added added

* Ascospores of $N$. tetrasperma and conidia of the other species were used.

Table 6. Percentage germination of fungal spores on nutrient agarose blocks preincubated on synthetic soils containing different groups of non-antibiotic-producing micro-organisms

Synthetic soils were inoculated with (1) five isolates each of bacteria, actinomycetes and fungi, (2) five isolates of bacteria, (3) five isolates of actinomycetes and (4) five isolates of fungi, and incubated at $24^{\circ} \mathrm{C}$ for at least 1 month before use. The final populations of micro-organisms in $1 \mathrm{~g}$ soil were: (1) $6.1 \times 10^{7}$ bacteria, $3.6 \times 10^{6}$ actinomycetes and $1.6 \times 10^{6}$ fungi; (2) $1.0 \times 10^{8}$ bacteria; (3) $8.1 \times 10^{6}$ actinomycetes; and (4) $4.5 \times 10^{6}$ fungi. Nutrient agarose blocks $(0.8 \%$ SeaKem agarose, $100 \mu \mathrm{g}$ glucose $\mathrm{ml}^{-1}$ and $100 \mu \mathrm{g}$ peptone $\mathrm{ml}^{-1}$ ) placed on polycarbonate membranes were incubated on the surface of synthetic soil at $24^{\circ} \mathrm{C}$ for $24 \mathrm{~h}$, then transferred to sterile Petri dishes and tested for spore germination. The data are from one of two experiments with similar results. More than 200 spores were counted in each treatment for each experiment.

Micro-organisms added to synthetic soil:

Test fungus*
N. tetrasperma
B. maydis
B. stenospila
E. rostratum
M. ramannianus
P. frequentans
$P$. funiculosum

\begin{tabular}{ccccc}
\hline Mixed & Bacteria & Actinomycetes & Fungi & None \\
99 & 99 & 99 & 100 & 99 \\
98 & 99 & 99 & 100 & 93 \\
99 & 100 & 100 & 99 & 99 \\
98 & 98 & 98 & 99 & 100 \\
3 & 70 & 84 & 13 & 99 \\
4 & 68 & 58 & 61 & 99 \\
8 & 36 & 17 & 20 & 100
\end{tabular}

* Ascospores of $N$. tetrasperma and conidia of the other species were used. 


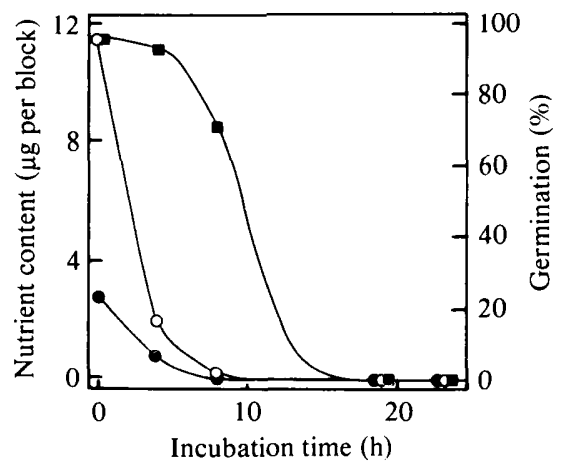

Fig. 3. Relationship between loss of soluble carbohydrates $(O)$ and amino acids $(O)$ from nutrient

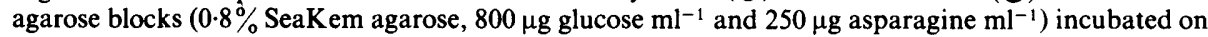
synthetic soil at $24^{\circ} \mathrm{C}$ and their ability to support spore germination of $P$. frequentans $(\square)$. The synthetic soil contained five isolates each of non-antibiotic-producing bacteria, actinomycetes and fungi.

$(10 \times 7.5 \times 2 \mathrm{~mm})$ were placed on polycarbonate membranes and incubated on natural soil or synthetic soil at $24{ }^{\circ} \mathrm{C}$ for $24 \mathrm{~h}$, then transferred to sterile Petri plates and tested for spore germination as previously described. Both nutrient-independent and nutrient-dependent fungi germinated on nutrient agarose blocks preincubated on synthetic soil without micro-organisms added (Table 5). Preincubation on natural soil or synthetic soil inoculated with mixed microorganisms rendered the nutrient agarose blocks incapable of supporting germination of nutrient-dependent fungi without reducing their ability to support germination of nutrientindependent fungi.

The same method was used to study the ability of different groups of micro-organisms to create a sink effect in soil. Although all the nutrient-independent fungi germinated completely, germination of nutrient-dependent fungi was reduced to various levels on nutrient agarose blocks preincubated on synthetic soils inoculated with bacteria, actinomycetes and fungi (Table 6). However, individual groups of micro-organisms were not as effective as mixed microorganisms in causing diffusion of nutrients.

More than $80 \%$ of soluble carbohydrates and $70 \%$ of amino acids diffused from agarose blocks within $4 \mathrm{~h}$ and about $99 \%$ of each group of compounds was lost after $17 \mathrm{~h} \mathrm{(Fig.} \mathrm{3).} \mathrm{The}$ germination of $\boldsymbol{P}$. frequentans on agarose blocks also decreased with increasing time of incubation on synthetic soil. No germination occurred on agarose blocks after $17 \mathrm{~h}$ incubation.

\section{DISCUSSION}

The inability of micro-organisms to multiply in natural soil could be due either to the presence of inhibitors or to the absence of nutrients required for microbial growth. In the study of fungistasis, inhibitors have been detected in certain soils but none has met the minimum criteria for being the cause of soil fungistasis (Ko \& Lockwood, 1967; Lockwood, 1984). Ko \& Lockwood (1967) proposed that soil fungistasis is a result of nutrient deprivation imposed by microbial activity in soil. Leaching systems were developed to demonstrate that a strong diffusion gradient of nutrients, presumed to be caused by microbial activity in soil, can inhibit germination of nutrient-independent fungi (Ko \& Lockwood, 1967; Hsu \& Lockwood, 1973). However, the ability of micro-organisms to create a 'nutrient sink' in soil cannot be tested in such systems. This problem was overcome by the development of a synthetic soil which contained micro-organisms from natural soil.

Several lines of evidence suggest the similarity of synthetic soil to natural soil. (i) The germination pattern of fungi on synthetic soil corresponds to that on natural soil. (ii) Agarose blocks become inhibitory to nutrient-dependent fungi but not to nutrient-independent ones after 
incubation with either synthetic or natural soil. (iii) Like natural soil, synthetic soil becomes non-fungistatic after sterilization. (iv) Nutrients diffuse to both synthetic and natural soils from agarose blocks placed on these soils. (v) The germination patterns on natural and synthetic soils mixed with various amounts of silica sand are similar. (vi) Like natural soil, synthetic soil also induces lysis of fungal mycelia.

Each component of the synthetic soil was shown to be free from inhibitors and nutrients. The nutrient-independent fungi germinated freely, whereas the nutrient-dependent fungi germinated poorly in each separate component of synthetic soil. Before addition of micro-organisms, $1 \mathrm{~g}$ synthetic soil contained 88 bacteria and 71 actinomycetes but no fungi. The original microorganisms were very few and insignificant in comparison with the numbers of micro-organisms added subsequently. It is very unlikely that the original micro-organisms had become prominent later, because the added micro-organisms maintained a relatively constant population in synthetic soil during the 3 month incubation. Since non-antibiotic-producing micro-organisms were used and agarose blocks preincubated with synthetic soil were inhibitory to nutrientdependent but not nutrient-independent fungi, the synthetic soil was considered to be free of inhibitors of both abiotic and microbial origin. Conidia of $B$. maydis, B. stenospila and $E$. rostratum germinated completely in distilled water but failed to germinate on the synthetic soil. Agarose blocks incubated on synthetic soil rapidly lost nutrients and the ability to support germination of $P$. frequentans at the same time. These results strongly support the hypothesis that microbial activity of soil creates a strong diffusion gradient of nutrients which in turn causes the inhibition of germination of nutrient-independent fungal spores (Ko \& Lockwood, 1967).

Non-antibiotic-producing micro-organisms were as effective as antibiotic-producing microorganisms in inducing fungistasis in synthetic soil. This suggested that inhibitors of microbial origin do not play a significant role in fungistasis. If nutrient deprivation imposed by microbial activity is the main reason for the failure of nutrient-independent fungi to germinate in soil, germination should occur when the microbial population is decreased. This was exactly what happened when natural soils and synthetic soils were diluted with silica sand which was free of both nutrients and micro-organisms. The percentage germination of B. maydis and E. rostratum in both soils increased with increasing proportion of silica sand.

The characteristics of soil microbiostasis are similar to those of soil fungistasis, so nutrient deprivation inflicted by microbial activity has also been considered to be the main cause of soil microbiostasis (Ko \& Chow, 1977; Ko, 1982; Lynch, 1982; Ko \& Ho, 1984; Lockwood, 1984). This hypothesis is supported by the results of the present experiments with synthetic soil. The populations of bacteria, actinomycetes and fungi remained more or less unchanged in synthetic soil consisting of inhibitor-free abiotic components and non-antibiotic-producing microorganisms. Moreover, microbiostasis disappeared when micro-organisms in synthetic soil were killed by sterilization.

The nutrient deficiency hypothesis permits a simple explanation for many aspects of soil microbiostasis, e.g. (i) its widespread occurrence in most soils tested (Ho \& Ko, 1982); (ii) restoration of microbiostasis to sterilized soil by infestation with non-antibiotic-producing micro-organisms (Ho \& Ko, 1982); (iii) differential effect of nutrients on bacteriostasis, actinostasis and fungistasis (Ho \& Ko, 1982; Ko, 1982); (iv) annulment of microbiostasis by freezing treatment (Ho \& Ko, 1985).

This study was supported in part by a grant from the East-West Center to the senior author. Journal Series no. 3014 of the Hawaii Institute of Tropical and Human Resources.

\section{REFERENCES}

ARAGaKI, M. (1964). Relation of radiation and temperature to the sporulation of Alternaria tomato and other fungi. Phytopathology 54, 565-569.

Brown, M. E. (1973). Soil bacteriostasis limitation in growth of soil and rhizosphere bacteria. Canadian Journal of Microbiology 19, 195-199.
DobBs, C. G. \& Hinson, W. H. (1953). A widespread fungistasis in soils. Nature, London 172, 197-199.

Farley, J. D. \& Lockwood, J. L. (1968). The suppression of actinomycetes by PCNB in culture media for enumerating soil bacteria. Phytopathology 58, 1714-1715. 
Ho, W. C. \& Ko, W. H. (1980a). Agarose medium for bioassay of antimicrobial substances. Phytopathology 70, 764-766.

Ho, W. C. \& Ko, W. H. (1980b). A simple medium for selective isolation and enumeration of soil actinomycetes. Annals of the Phytopathological Society of Japan 46, 634-638.

Ho, W. C. \& Ko, W. H. (1982). Characteristics of soil microbiostasis. Soil Biology and Biochemistry 14, 589-593.

Ho, W. C. \& Ko, W. H. (1985). Soil microbiostasis: effects of environmental and edaphic factors. Soil Biology and Biochemistry 17, 167-170.

Hoagland, D. R. \& ARnon, D. I. (1950). The waterculture method for growing plants without soil. California Agricultural Experiment Station Circular no. 347.

Hsu, S. C. \& Lockwood, J. L. (1973). Soil fungistasis: behavior of nutrient-independent spores and sclerotia in a model system. Phytopathology 63, 334-337.

KATZNELSON, H. (1940). Survival of microorganisms introduced into soil. Soil Science 49, 283-293.

Ko, W. H. (1982). Effects of nutritional factors on chemical and soil microbiostasis. University of Hawaii HITAHR Research Series 12, 1-55.

Ko, W. H. \& CHOw, F. K. (1976). Characteristics of soil bacteriostasis. Proceedings of the American Phytopathological Society 3, 239.

Ko, W. H. \& CHow, F. K. (1977). Characteristics of bacteriostasis in natural soil. Journal of General Microbiolgy 102, 295-298.

Ko, W. H. \& Ho, W. C. (1984). Soil microbiostasis. In
Soilborne Crop Diseases in Asia, pp. 175-184. Edited by J. Bay-Petersen. Taipei: Food \& Fertilizer Technology Center

Ko, W. H. \& Lockwood, J. L. (1967). Soil fungistasis: relation to fungal spore nutrition. Phytopathology 57, 894-901.

Ko, W. H. \& Lockwood, J. L. (1970). Mechanism of lysis of fungal mycelia in soil. Phytopathology 60, 148-154.

LOcKWOOD, J. L. (1960). Lysis of mycelium of plantpathogenic fungi by natural soil. Phytopathology 50, 787-789.

LockwoOD, J. L. (1984). Soil fungistasis : mechanisms and relation to biological control of soilborne plant pathogens. In Soilborne Crop Diseases in Asia, pp. 159-174. Edited by J. Bay-Petersen. Taipei: Food \& Fertilizer Technology Center.

LYNCH, J. M. (1982). Limits of microbial growth in soil. Journal of General Microbiology 128, 405-410.

MOORE, S. \& STEIN, W. H. (1955). A modified ninhydrin reagent for the photometric determination of amino acids and related compounds. Journal of Biological Chemistry 211, 907-913.

MORRIS, D. L. (1958). Quantitative determination of carbohydrates with Dreywood's anthrone reagent. Science 107, 254-255.

Russell, E. J. \& Hutchinson, H. B. (1909). The effect of partial sterilization of soil on the production of plant food. Journal of Agricultural Science 3, 111-144. Steiner, G. W. \& Watson, R. D. (1965). Use of surfactants in the soil dilution and plate count method. Phytopathology 55, 728-730. 